\title{
Longitudinal association of dietary sources of animal and plant protein throughout childhood with menarche
}

\author{
Nazanin Moslehi ${ }^{1}$, Golaleh Asghari ${ }^{1,2^{*}}$, Parvin Mirmiran ${ }^{1,2^{*}}$ and Fereidoun Azizi ${ }^{3}$
}

\begin{abstract}
Background: Inconsistent findings have been reported for associations between protein intake and age at menarche. We aimed to investigate the association between intake of protein and protein-containing food groups during childhood with menarche among Iranian girls.

Methods: Girls aged 6-18 years who did not experience menarche in the third or fourth examination cycles of the Tehran Lipid and Glucose Study were selected and were followed to the fifth examination cycle. Daily intakes of protein from different animal/plant sources and ten protein-containing food groups were assessed using a food frequency questionnaire at baseline (the third or fourth examination cycles). Occurrence of menarche and its onset age were asked during each examination cycle. Cox proportional hazards regression was used to estimating hazard ratios (HRs) and 95\% confidence interval $(95 \% \mathrm{Cl})$ for the occurrence of menarche per one standard deviation (SD) of dietary intakes. Logistic regression was also used to estimate the odds of reaching menarche $\leq 12$ years.
\end{abstract}

Results: During the study, 147(61\%) of girls reached menarche, the median age at menarche was 12 years. The adjusted HRs $(95 \% \mathrm{Cl})$ for the occurrence of menarche per one-SD of dietary intakes were $0.68(0.48,0.98 ; p=0.040)$ for plant protein and $1.36(1.01,1.84 ; p=0.042)$ for animal protein after adjusting for baseline age, BMI Z-score, energy intake, and mother's early menarche and education. Substituting 10-g animal protein with plant protein was associated with a 16\% (95\%Cl: 5-25\%; $p=0.006)$ lower risk of menarche. Dietary intakes of poultry (adjusted HR: $1.35 ; 95 \%$ Cls: $1.00-1.82 ; p=0.049$ ) and low-fat dairy (adjusted HR: 1.20; 95\%Cls: 0.99-1.46; $p=0.064$ ) were marginally associated with the increased risk of menarche. However, the odds of early menarche was significant only for plant protein (adjusted odds ratio $=0.39 ; 95 \%$ Cl: $0.16-0.96 ; p=0.040$ ).

Conclusions: Our findings indicate that the risk of menarche increases by higher intakes of animal protein and decreases by plant protein. Intakes of poultry and low-fat dairy associate with a higher risk of menarche. The odds of menarche occurrence $\leq 12$ years reduces by higher intakes of plant protein.

Keywords: Plant protein, Animal protein, Menarche, Dairy, Meat

\footnotetext{
*Correspondence: g_asghari@hotmail.com; mirmiran@endocrine.ac.ir ${ }^{1}$ Nutrition and Endocrine Research Center, Research Institute for Endocrine Sciences, Shahid Beheshti University of Medical Sciences, No. 24, Shahid Arabi St, Yemen Blvd, Chamran Exp, P.O.Box: 19395-4763, Tehran, Iran Full list of author information is available at the end of the article
} 


\section{Background}

Menarche, as the late stage of reproductive development, represents sexual maturation in girls [1]. In recent years, the average age at menarche (AAM) has decreased worldwide due to an improved lifestyle and nutritional status [2]. In Iran, a reduction of 0.15 years per decade in menarcheal age was estimated between 1930 and 1990 [3]. The age when an adolescent girl first begins menses affects their sexual and reproductive health as well as non-reproductive health [4]. Earlier age at menarche has been associated with a higher risk of metabolic syndrome $[5,6]$, type 2 diabetes $[7,8]$, hormonerelated cancers $[9,10]$, cardiovascular disease, and mortality later in life during adulthood [11]. In Iranian women, the risk of pre-diabetes, diabetes, and metabolic syndrome was 2.3-3.6 higher in women with menarcheal age $<11$ than those with menarcheal age 13-14 years $[6,8]$. It has also been estimated that the risk of type 2 diabetes is reduced by $9 \%$ per 1 -year later occurrence of menarche [7], and the risk of metabolic syndrome is increased by $8 \%$ per 1 -year decrease in AAM [5].

Although genetic factors are the main determinants of timing of menarche, non-genetic variables such as dietary intakes may provide clues on early intervention to prevent menarche at early ages $[12,13]$. Studies on associations of nutritional factors with AAM have a long history, yet few of the menarche's dietary determinants have been characterized. Considering dietary sources of protein intake, prospective studies conducted in US and German girls suggested an inverse association for animal protein and a positive association for plant protein with AAM $[14,15]$. The positive association between animal protein intake and AAM was also reported in girls living in south-west England, while plant protein intake was not associated with menarche [16]. Of proteincontaining food groups, dietary intakes of dairy and meats have been mostly investigated, particularly in the Western countries [16-21]. However, the findings of the studies are highly inconsistent. Apart from null results $[16,20]$, dairy intake was associated with either a lower AAM [18] or a higher AAM [19, 21]. Red meat consumption in south-west England and Colombian girls were reported to be associated with a lower AAM [16, 20], while in the US girls, red meat intake was not related to the likelihood of attaining menarche [19]. Besides, the other dietary sources of protein intake have been less studied concerning AAM. Differences in the availability of foods, cooking methods, and dietary pattern across geographical regions may influence the nutritional determinants of menarche. Since there have been scarce studies in the Middle East and North Africa region, we examined whether total protein, protein intake from animal/plant sources, and specific protein- containing food groups are associated with menarche among Iranian girls.

\section{Methods \\ Participants}

The Tehran Lipid and Glucose Study (TLGS) is a prospective population-based study started in 1999 with 15, 005 individuals aged $\geq 3$ years. The participants were selected randomly from residents of district No. 13, Tehran, the capital of Iran. Extensive information on participants' socio-economic and health has been collected at baseline and updated every 3-years after that [22]. In this study, all girls aged 6-18 years at either the TLGS third (2005-2008; $n=294)$ or the fourth (20082011; $n=417$ ) examination cycles were selected. After exclusion of those who had already had menarche $(n=$ 440) and those with missing information for menstrual status $(n=4)$ or lost to follow-up $(n=26), 241$ girls were followed to the fifth examination cycle (2012-2015; Fig. 1).

This study was conducted following the principles of the Declaration of Helsinki; written informed consent was obtained from parents or primary caregivers of all girls.

\section{Data collection \\ Age at menarche}

During each examination cycle of the study, the menstruation status of females was assessed using a questionnaire. Girls were asked whether they reached menarche and if yes, the age at which they had attained the menarche was asked in complete years. Maternal menarcheal age was determined based on their selfreporting of the age of initiation of menstruation. The occurrence of menarche at $\leq 12$ years was defined as early menarche based on the median age of menstruation onset of girls. The age of 12 years was also consistent with the AAM of Tehranian girls in TLGS minus one standard deviation (SD) [3].

\section{Dietary intakes}

Dietary intakes were assessed by a food frequency questionnaire (FFQ) collected either at the third or fourth examination cycles (Supplementary file 1). The frequency and amount of each food item consumed during the past year were assessed using the FFQ and converted to g/day. Intakes of energy and nutrients were determined using the United States Department of Agriculture (USDA) and the Iranian food composition tables $[23,24]$. Intakes of total protein, protein from animal and plant sources, and intake of 10 protein-containing food groups including fast food, red meat, poultry, fish, organ meat, egg, legumes, low-fat dairy, high-fat dairy, and total dairy were estimated. 


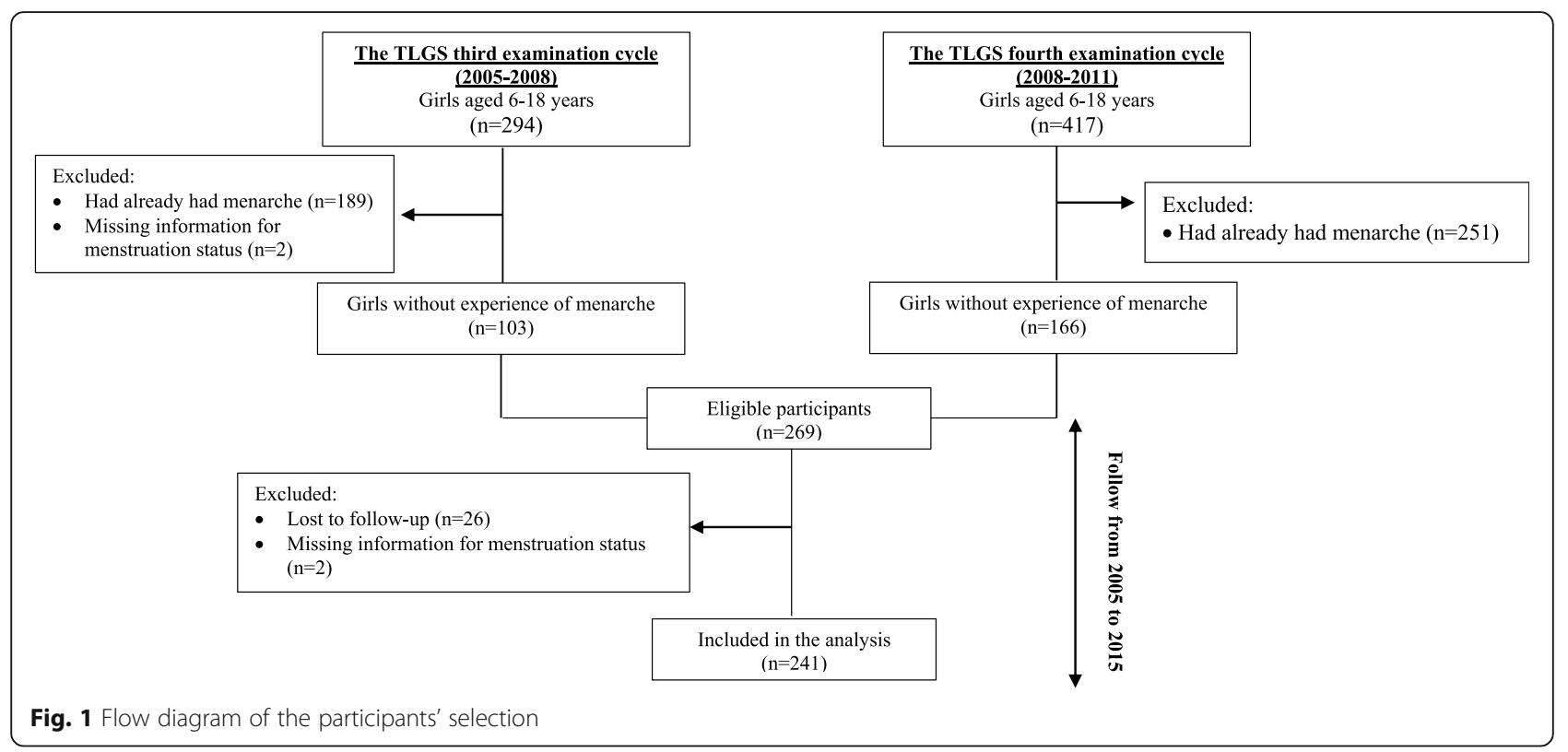

\section{Demographic and anthropometric data}

Girls' ages were determined according to their birth date. Maternal education was assessed by a questionnaire and categorized into three groups: education less than 12 years, 12 years, and academic education.

Weight and height were measured, and body mass index (BMI) was calculated. Age-specific z-scores of height and BMI for girls were computed using 2007 WHO reference data [25].

\section{Statistical analysis}

The normality assumption of each variable was checked using the Kolmogorov-Smirnov test and histogram chart. Baseline characteristics and dietary intakes of girls based on attaining the menarche were determined and compared using Student T-test (for normally distributed variables), Mann-Whitney (for skewed variables), and Chi-square (for categorical variables). Cox proportional hazard regression was used to estimating hazard ratios (HRs) and 95\% confidence interval $(95 \% \mathrm{CI})$ for the occurrence of menarche per one standard deviation (SD) of dietary intakes. Censored date (in days) was calculated from the date of entrance to the study to the date of menarche occurrence or the date of the last follow-up for each participant, whichever came first. The proportionality hazards $(\mathrm{PH})$ assumption was evaluated by correlation tests of Schoenfeld residuals and event time using STATA (version 12; STATA Inc., TX, USA). All proportionality assumptions were generally satisfied. Logistic regression was also used to estimate odds of reaching menarche $\leq 12$ years using the data of girls aged $\geq 12$ years at follow-up $(n=161)$. For both Cox and logistic regression analyses, three models were constructed as: a) unadjusted, b) adjusted for baseline age and BMI Zscore, energy intake, and maternal early menarche (yes/ no), and C) additionally adjusted for maternal education (three categories).

Substitution analysis was done to estimate the risk of menarche and early menarche by substituting plant protein for animal protein while holding the total consumption of animal and plant protein constant in the fully adjusted model using the leave-one-out model [26]. Based on the model, one type of protein (animal /plant) was replaced by another while holding total protein intake constant. For example, in substitution of plant protein for animal protein, the multivariable model included plant protein and total protein consumption (animal protein was not included). Dietary intake of animal/plant protein was divided by 10 to generate substitution results for their 10-g dietary intakes.

\section{Results}

The baseline characteristics of the study population are presented in Table 1 . The mean \pm SD of age at baseline was $9.6 \pm 1.9$ years (ranges $6-14$ years), and $61 \%$ of girls reached menarche during the study. The median age at menarche was 12 years, with the range between 9 and 16. Age and height and BMI z-score of girls who attained the menarche were higher than those who did not experience menarche. Dietary intakes were not significantly different between the two groups, except for plant protein and high-fat dairy.

After adjusting for baseline age, BMI, energy intakes, and mother's early menarche, the adjusted HRs $(95 \% \mathrm{CI})$ for menarche were 1.40 (95\% CI: $1.04-1.88 ; p=0.028$ ) for poultry, 1.24 (95\% CI: $1.03-1.50 ; p=0.025)$ for low- 
Table 1 Baseline characteristics of participants ${ }^{a}$

\begin{tabular}{|c|c|c|c|c|}
\hline Variables & Total $(n=241)$ & Menarche $(n=147)$ & No menarche $(n=94)$ & $p$-value ${ }^{\mathrm{b}}$ \\
\hline Age & $9.64 \pm 1.91$ & $10.63 \pm 1.49$ & $8.08 \pm 1.40$ & $<0.001$ \\
\hline BMI z-score & $0.40 \pm 1.71$ & $0.70 \pm 1.69$ & $-0.07 \pm 1.63$ & 0.001 \\
\hline Height z-score & $0.51 \pm 0.99$ & $0.20 \pm 0.99$ & $-0.18 \pm 0.94$ & 0.004 \\
\hline Maternal age at menarche & $13.6 \pm 1.4$ & $13.5 \pm 1.5$ & $13.7 \pm 1.3$ & 0.312 \\
\hline Maternal early menarche & $46(19.4)$ & $30(20.7)$ & $16(17.4)$ & 0.532 \\
\hline \multicolumn{5}{|l|}{ Maternal education } \\
\hline$<12$ years & $47(19.7)$ & $32(21.9)$ & $15(16.3)$ & \multirow[t]{3}{*}{0.215} \\
\hline 12 years & $137(57.6)$ & $86(58.9)$ & $51(37.2)$ & \\
\hline Academic education & $54(22.7)$ & $28(19.2)$ & $26(28.3)$ & \\
\hline \multicolumn{5}{|l|}{ Daily dietary intake } \\
\hline Energy (kcal) & $2328(1829-3135)$ & $2382(1900-3269)$ & $2193(1768-2908)$ & 0.069 \\
\hline Plant protein (\% of energy) & $5.57(4.80-6.84)$ & $5.84(4.92-6.99)$ & $5.35(4.49-6.42)$ & 0.031 \\
\hline Animal protein (\% of energy) & $6.95(5.56-8.98)$ & $6.89(5.31-8.91)$ & $6.99(5.76-9.01)$ & 0.459 \\
\hline Total protein (\% of energy) & $13.10(11.81-14.28)$ & $13.19(11.85-14.40)$ & $12.85(11.74-14.22)$ & 0.469 \\
\hline Fat food (g/1000 kcal) & $5.55(2.68-10.05)$ & $6.29(2.94-10.32)$ & $5.07(2.50-9.37)$ & 0.281 \\
\hline Red meat (g/1000 kcal) & $4.52(2.27-8.90)$ & $4.22(2.31-8.67)$ & $4.96(2.23-10.23)$ & 0.444 \\
\hline Poultry (g/1000 kcal) & $6.58(3.67-12.18)$ & $6.83(3.47-12.11)$ & $6.31(3.82-12.42)$ & 0.797 \\
\hline Fish (g/1000 kcal) & $3.06(1.53-5.65)$ & $3.08(1.50-5.57)$ & $2.94(1.66-6.02)$ & 0.928 \\
\hline Organ meat (g/1000 kcal) & $0.28(0.04-0.69)$ & $0.27(0.05-0.69)$ & $0.29(0.03-0.69)$ & 0.629 \\
\hline Egg (g/1000 kcal) & $5.12(2.73-8.85)$ & $5.91(3.03-9.33)$ & $4.81(2.47-8.33)$ & 0.294 \\
\hline Legumes (g/1000 kcal) & $9.65(4.38-17.25)$ & $9.99(4.29-17.38)$ & $9.13(4.56-17.23)$ & 0.829 \\
\hline Low-fat dairy (g/1000 kcal) & $94.2(51.8-149.4)$ & $91.1(46.1-175.9)$ & $103.5(56.4-147.0)$ & 0.829 \\
\hline High-fat dairy (g/1000 kcal) & $92.4(38.7-143.8)$ & $83.7(34.7-130.7)$ & $111.0(41.7-167.5)$ & 0.035 \\
\hline Total dairy (g/1000 kcal) & $203(138-296)$ & $193(138-291)$ & 209 (147-299) & 0.202 \\
\hline
\end{tabular}

${ }^{\mathrm{a} D a t a}$ was reported as mean $\pm \mathrm{SD}$, median (quartile 25 -quartile 75 ), or number (\%). ${ }^{\mathrm{b}}$ Based on Student T-test and Mann-Whitney test for continuous variables and chi-square for categorical variables

fat dairy, 0.65 (95\% CI: $0.46-0.93 ; p=0.018)$ for plant protein, and $1.44(95 \% \mathrm{CI}=1.07-1.94 ; p=0.015)$ for animal protein per 1-SD dietary intakes. The association between low-fat dairy and menarche became nonsignificant after further inclusion of the mother's educational levels into the model, but the other associations remained significant (Table 2). When plant protein replaced animal protein, the risk of menarche reduced 16\% (95\%CI: $5-25 \% ; p=0.006)$ per 10 -g dietary intakes after adjusting for all covariates.

In the unadjusted model, the odds of early menarche increased by $90 \%$ and decreased by $41 \%$ per $1-\mathrm{SD}$ of poultry and plant protein intakes, respectively. Adjustment for baseline age, BMI, energy intake, mother's early menarche, and educational level attenuated odds ratio (OR) for poultry (adjusted OR $=1.42,95 \%$ CI: $0.65-3.11$; $p=0.378)$, but the association remained significant for plant protein (adjusted OR $=0.39,95 \%$ CI: 0.16-0.96; $p=0.040$ ) (Table 3 ). The odds of early menarche was not significant by substituting animal protein with plant protein in the fully adjusted model.

\section{Discussion}

In this prospective study, animal protein intake increased and plant protein decreased the risk of menarche. Considering protein-containing foods, higher intakes of poultry and low-fat dairy increased odds of menarche. The odds of early menarche decreased with higher intakes of plant protein; neither animal protein nor protein-containing foods were associated with odds of early menarche.

Similar to our findings, previous studies concerning the association between different protein intake sources and menarche consistently reported that girls attain menarche earlier by consuming more animal protein during childhood; however, the timing in which animal protein intake may influence menarche is controversial [14-16]. Animal protein during the entire childhood period from ages of 3-5 year, 6-8 years, and 2 years before peak growth velocity in the US girls was a predictor of AAM [14], while animal protein at age 3 and 7 but not 10 years in girls living in South-West England were associated with earlier menarche [16]. In contrast, in the 
Table 2 Hazard ratios (95\% confidence intervals) for the occurrence of menarche based on 1-standard deviation for dietary intakes of protein-containing food groups

\begin{tabular}{|c|c|c|c|}
\hline Dietary intakes (g) & Model 1 & Model 2 & Model 3 \\
\hline Total protein & $1.15(0.99-1.34)$ & $1.28(0.81-2.03)$ & $1.22(0.78-1.93)$ \\
\hline$p$-value & 0.068 & 0.293 & 0.385 \\
\hline Animal protein & $1.14(0.94-1.39)$ & $1.44(1.07-1.94)$ & $1.36(1.01-1.84)$ \\
\hline$p$-value & 0.173 & 0.015 & 0.042 \\
\hline Plant protein & $1.17(0.99-1.38)$ & $0.65(0.46-0.93)$ & $0.68(0.48-0.98)$ \\
\hline$p$-value & 0.066 & 0.018 & 0.040 \\
\hline Fat food & $1.10(0.91-1.32)$ & $1.01(0.80-1.26)$ & $0.96(0.77-1.20)$ \\
\hline$p$-value & 0.314 & 0.955 & 0.719 \\
\hline Red meat & $1.04(0.83-1.33)$ & $1.16(0.90-1.49)$ & $1.12(0.87-1.44)$ \\
\hline$p$-value & 0.715 & 0.248 & 0.375 \\
\hline Poultry & $1.06(0.79-1.41)$ & $1.40(1.04-1.88)$ & $1.35(1.00-1.82)$ \\
\hline$p$-value & 0.709 & 0.028 & 0.049 \\
\hline Fish & $1.17(0.93-1.47)$ & $0.96(0.75-1.23)$ & $0.93(0.72-1.20)$ \\
\hline$p$-value & 0.188 & 0.750 & 0.577 \\
\hline Organ meat & $1.02(0.74-1.40)$ & $0.89(0.63-1.26)$ & $0.86(0.61-1.22)$ \\
\hline$p$-value & 0.913 & 0.518 & 0.404 \\
\hline Egg & $1.09(0.91-1.31)$ & $1.19(0.99-1.43)$ & $1.16(0.97-1.40)$ \\
\hline$p$-value & 0.334 & 0.070 & 0.109 \\
\hline Legumes & $1.08(0.91-1.27)$ & $0.90(0.74-1.10)$ & $0.95(0.77-1.18)$ \\
\hline$p$-value & 0.400 & 0.316 & 0.651 \\
\hline Low-fat dairy & $1.12(0.94-1.34)$ & $1.24(1.03-1.50)$ & $1.20(0.99-1.46)$ \\
\hline$p$-value & 0.215 & 0.025 & 0.064 \\
\hline High-fat dairy & $0.96(0.80-1.15)$ & $0.88(0.72-1.07)$ & $0.90(0.73-1.10)$ \\
\hline$p$-value & 0.629 & 0.195 & 0.307 \\
\hline Total dairy & $1.04(0.87-1.25)$ & $1.07(0.86-1.33)$ & $1.06(0.85-1.33)$ \\
\hline$p$-value & 0.628 & 0.547 & 0.576 \\
\hline
\end{tabular}

Model 1: Unadjusted

Model 2: Adjusted for baseline age, BMI Z-score, energy intake, and mother's early menarche

Model 3: Adjusted for baseline age, BMI Z-score, energy intake, and mother's early menarche and education

German girls, animal protein intakes at age 5-6 years but not at ages 3-4 years were associated with early menarche [15]. Plant protein intake at the age of 3-5 years was suggested as a predictor of menarche in the US girls, but no significant association was indicated between plant protein intake after the age of 5 years [14] while in the German girls, plant protein intakes at the age of 3-6 years were associated with later age at menarche [15]. Our findings showed that dietary intakes of plant protein at ages between 6 to 14 years were related to menarche.

Interestingly, the percent of animal and plant protein from total energy intakes did not differ across the age groups from early to late childhood, according to Berkey et al. and Gunther et al. studies [14, 15]. In our study, animal protein was about $7 \%$ of energy intake, which
Table 3 Odds ratios (95\% confidence intervals) for early menarche based on 1-standard deviation for dietary intakes of protein-containing food groups

\begin{tabular}{|c|c|c|c|}
\hline Dietary intakes (g) & Model 1 & Model 2 & Model 3 \\
\hline Total protein & $0.80(0.58-1.10)$ & $0.63(0.26-1.51)$ & $0.56(0.22-1.39)$ \\
\hline$p$-value & 0.167 & 0.298 & 0.208 \\
\hline Animal protein & $0.98(0.70-1.39)$ & $1.25(0.65-2.42)$ & $1.20(0.62-2.33)$ \\
\hline$p$-value & 0.928 & 0.505 & 0.583 \\
\hline Plant protein & $0.59(0.40-0.88)$ & $0.40(0.16-0.98)$ & $0.39(0.16-0.96)$ \\
\hline$p$-value & 0.010 & 0.046 & 0.040 \\
\hline Fat food & $0.79(0.54-1.14)$ & $0.74(0.46-1.18)$ & $0.77(0.48-1.24)$ \\
\hline$p$-value & 0.204 & 0.207 & 0.279 \\
\hline Red meat & $1.34(0.85-2.11)$ & $1.84(0.93-3.62)$ & $1.90(0.96-3.76)$ \\
\hline$p$-value & 0.205 & 0.078 & 0.067 \\
\hline Poultry & $1.90(1.01-3.55)$ & $1.46(0.67-3.20)$ & $1.42(0.65-3.11)$ \\
\hline$p$-value & 0.046 & 0.344 & 0.378 \\
\hline Fish & $0.79(0.51-1.23)$ & $0.86(0.45-1.64)$ & $0.83(0.42-1.62)$ \\
\hline$p$-value & 0.291 & 0.640 & 0.583 \\
\hline Organ meat & $0.74(0.39-1.42)$ & $0.63(0.27-1.47)$ & $0.66(0.28-1.57)$ \\
\hline$p$-value & 0.368 & 0.284 & 0.348 \\
\hline Egg & $0.89(0.62-1.28)$ & $0.85(0.53-1.36)$ & $0.85(0.53-1.38)$ \\
\hline$p$-value & 0.531 & 0.490 & 0.515 \\
\hline Legumes & $1.06(0.75-1.50)$ & $1.19(0.74-1.91)$ & $1.18(0.73-1.91)$ \\
\hline$p$-value & 0.737 & 0.465 & 0.489 \\
\hline Low-fat dairy & $0.98(0.72-1.33)$ & $1.05(0.69-1.59)$ & $1.02(0.67-1.55)$ \\
\hline$p$-value & 0.879 & 0.820 & 0.928 \\
\hline High-fat dairy & $0.91(0.66-1.26)$ & $1.14(0.72-1.80)$ & $1.07(0.66-1.72)$ \\
\hline$p$-value & 0.568 & 0.567 & 0.793 \\
\hline Total dairy & $0.92(0.67-1.25)$ & $1.14(0.71-1.81)$ & $1.06(0.65-1.73)$ \\
\hline$p$-value & 0.596 & 0.596 & 0.828 \\
\hline
\end{tabular}

Model 1: Unadjusted

Model 2: Adjusted for baseline age, BMI Z-score, energy intake, and mother's early menarche

Model 3: Adjusted for, baseline age, BMI Z-score, energy intake, and mother's early menarche and education

was lower than that in the US girls (about 9\% energy intake) and in the German girls (about $8 \%$ of the energy intake) $[14,15]$. Besides, the plant protein was $5.6 \%$ of energy intakes, which was higher compared to the US girls (3.78\% of energy) and the German girls (4.3\% of energy) $[14,15]$.

Regarding evidence on dairy intake and AAM, two studies conducted in the US girls [17, 19]; one of which suggested a higher risk of early menarche in girls with higher intakes of milk at the age of 9-12 years [17], while the other one showed the later attaining menarche in girls with higher frequency intakes of total milk and low-fat milk at ages between 9 to 14 years [19]. In Chilean girls, also higher intakes of low-fat dairy, low-fat milk, and yogurt were associated with later AAM [21]. 
We have previously reported a higher odds of early menarche in girls who consumed more milk at the age of 4-12 years [18]. However, the other studies could not find any significant association between dairy and menarche $[16,20]$.

In our study, the intake of fast food and red meat was not associated with menarche. Contrary to our findings, Jansen et al. reported that red meat intake frequency was inversely associated with AAM [20]. Similarly, in the prospective investigation in the South-West England girls, meat intakes at both 7 years and 3 years were strongly positively related to menarche [16]. Consistent with our results, Carwile et al. could not find any significant association between girls' red-meat intake at the age of 9-14 years and AAM [19].

Other protein-containing foods such as poultry, fish, egg, and legumes have been less studied in relation to the AAM. In our study, poultry intake was inversely associated with menarche, although Jansen et al. could not show any relation between this food group and menarche among Colombian girls [20]. Fish intake has controversial findings associated with the risk of menarche [16, 20]; we could not find any association between fish intake and menarche. Limited studies have been conducted to investigate eggs and legumes intakes in relation to AAM, which provided non-significant results $[16,20]$.

The previous studies were more interested in investigating the associations of dietary intakes of protein during early to mid-childhood rather than late-childhood, which is close to the age of menarche, perhaps due to the possible effects of puberty on dietary intakes during the late-childhood periods [27]. Girls enter puberty between the ages of 8 and 13 [28]. The age of girls in our study ranged between 6 and 14 years; one-third of them were $\leq 8$ years (mid-childhood), reflecting that most of them had entered puberty. Regardless of the possible effect of puberty on dietary intakes, habitual intakes of children may not be stable from early to late childhood. Therefore it makes it difficult to rely on a one-time point of dietary assessment for investigation on menarche. We also found considerable variability among studies in terms of dietary assessment tools, definitions of each food group, it's unit (gram, serving, gram $/ 1000 \mathrm{kcal}$, etc.), and frequency (continuous, one serving/day, one serving/week, etc.). Besides, the substantial differences in the food products and the preferred food items consumption across the populations and food preparation methods render the evidence challenging to interpret collectively.

\section{Strengths and limitations of this study}

Considering different dietary protein sources as exposures, accounting for important covariates including maternal menarcheal age and education, and conducting substitution analysis besides the conventional analyses are the main strengths of the study. Our study does have its limitations; first, a small sample size reduces our ability to conduct subgroup analysis based on participants' baseline age. Second, because most of our participants entered puberty, the potential effects of each stage of puberty on dietary intakes could not be ruled out.

\section{Conclusions}

In conclusion, as the only one conducted in the Middle East and North Africa region, our study showed that animal protein increased the risk of menarche and plant protein decreased. Of protein-containing food groups, intakes of poultry and low-fat dairy were marginally associated with a higher risk of menarche. The odds of early menarche was reduced with higher intake of plant protein, although none of the protein-containing food groups was related to early menarche. Our findings suggested that partly substitution of animal protein with plant sources during childhood may postpone menarche's timing.

\section{Abbreviations \\ AAM: Age at menarche; BMI: Body mass index; Cls: Confidence intervals; FFQ: Food frequency questionnaire; HRs: Hazard ratios; OR: Odds ratio; SD: Standard deviation; TLGS: Tehran Lipid and Glucose Study; USDA: United States Department of Agriculture; WHO: World health organization}

\section{Supplementary Information}

The online version contains supplementary material available at https://doi. org/10.1186/s12887-021-02670-8.

Additional file 1.

\section{Acknowledgements}

We express our appreciation to the participants of TLGS for their collaboration and to the entire TLGS staff.

\section{Authors' contributions}

NM and GA conceptualized the study, carried out the analyses, and drafted the initial manuscript. PM and FA supervised the project and critically reviewed the manuscript. All authors have read and approved the final manuscript.

\section{Funding \\ This study was supported by Shahid Beheshti University of Medical Sciences (grant No. 12610-1).}

\section{Availability of data and materials}

The datasets analyzed during the current study are available from the corresponding author on reasonable request.

\section{Declarations}

Ethics approval and consent to participate

The ethics committee of the Research Institute for Endocrine Sciences of Shahid Beheshti University of Medical Sciences approved the study protocol (No.IR.SBMU.ENDOCRINE.REC.1396.472). This study was conducted following the principles of the Declaration of Helsinki; written informed consent was obtained from parents or primary caregivers of all girls. 


\section{Consent for publication}

Not applicable.

\section{Competing interests}

There is no conflict of interest.

\section{Author details}

${ }^{1}$ Nutrition and Endocrine Research Center, Research Institute for Endocrine Sciences, Shahid Beheshti University of Medical Sciences, No. 24, Shahid Arabi St, Yemen Blvd, Chamran Exp, P.O.Box: 19395-4763, Tehran, Iran. ${ }^{2}$ Department of Clinical Nutrition and Dietetics, Faculty of Nutrition and Food Technology, National Nutrition and Food Technology Research Institute, Shahid Beheshti University of Medical Sciences, No. 7, Arghavan-e-gharbi St., Farahzadi Blvd., Shahrak-e-qods, P.O.Box: 19395-4741, Tehran, Iran. ${ }^{3}$ Endocrine Research Center, Research Institute for Endocrine Sciences, Shahid Beheshti University of Medical Sciences, Tehran, Iran.

\section{Received: 9 December 2020 Accepted: 16 April 2021}

Published online: 28 April 2021

\section{References}

1. Abreu AP, Kaiser UB. Pubertal development and regulation. Lancet Diabetes Endocrinol. 2016;4(3):254-64. https://doi.org/10.1016/\$2213-8587(15)00418-0.

2. Euling SY, Selevan SG, Pescovitz OH, Skakkebaek NE. Role of environmental factors in the timing of puberty. Pediatrics. 2008;121(Suppl 3):S167-71. https://doi.org/10.1542/peds.2007-1813C.

3. Tehrani F, Mirmiran P, Zahedi Asl S, Nakhoda K, Azizi F. Menarcheal age of mothers and daughters: Tehran lipid and glucose study. East Mediterr Health J. 2010;16(4):391-5. https://doi.org/10.26719/2010.16.4.391.

4. Šaffa $G$, Kubicka AM, Hromada M, Kramer KL. Is the timing of menarche correlated with mortality and fertility rates? PLoS One. 2019;14(4):e0215462. https://doi.org/10.1371/journal.pone.0215462.

5. Kim Y, Je Y. Early menarche and risk of metabolic syndrome: a systematic review and meta-analysis. J Women's Health. 2019;28(1):77-86. https://doi. org/10.1089/jwh.2018.6998.

6. Farahmand M, Tehrani FR, Gandevani SB, Azizi F. Is there any association between age at menarche and risk of metabolic syndrome? The Tehran Lipid \& Glucose Study. Arch Iran Med. 2019;22(9):495-500.

7. Cheng TS, Day FR, Lakshman R, Ong KK. Association of puberty timing with type 2 diabetes: a systematic review and meta-analysis. PLoS Med. 2020; 17(1):e1003017. https://doi.org/10.1371/journal.pmed.1003017.

8. Farahmand M, Tehrani FR, Dovom MR, Azizi F. Menarcheal age and risk of type 2 diabetes: a community-based cohort study. J Clin Res Pediatr Endocrinol. 2017;9(2):156-62. https://doi.org/10.4274/jcrpe.3370.

9. Karageorgi S, Hankinson SE, Kraft P, De Vivo I. Reproductive factors and postmenopausal hormone use in relation to endometrial cancer risk in the Nurses' health study cohort 1976-2004. Int J Cancer. 2010;126(1):208-16. https://doi.org/10.1002/ijc.24672.

10. Cancer CGoHFiB. Menarche, menopause, and breast cancer risk: individual participant meta-analysis, including 118964 women with breast cancer from 117 epidemiological studies. Lancet Oncol. 2012;13(11):1141-51. https://doi.org/10.1016/S1470-2045(12)70425-4

11. Lakshman R, Forouhi NG, Sharp SJ, Luben R, Bingham SA, Khaw KT, et al. Early age at menarche associated with cardiovascular disease and mortality. J Clin Endocrinol Metab. 2009;94(12):4953-60. https://doi.org/10.1210/jc.2 009-1789.

12. Morris DH, Jones ME, Schoemaker MJ, Ashworth A, Swerdlow AJ. Familial concordance for age at menarche: analyses from the breakthrough generations study. Paediatr Perinat Epidemiol. 2011;25(3):306-11. https://doi. org/10.1111/j.1365-3016.2010.01183.x.

13. Yermachenko A, Dvornyk V. Nongenetic determinants of age at menarche: a systematic review. Biomed Res Int. 2014;2014:371583.

14. Berkey CS, Gardner JD, Frazier AL, Colditz GA. Relation of childhood diet and body size to menarche and adolescent growth in girls. Am J Epidemiol. 2000;152(5):446-52. https://doi.org/10.1093/aje/152.5.446.

15. Gunther AL, Karaolis-Danckert N, Kroke A, Remer T, Buyken AE. Dietary protein intake throughout childhood is associated with the timing of puberty. J Nutr. 2010;140(3):565-71. https://doi.org/10.3945/jn.109.114934.

16. Rogers IS, Northstone K, Dunger DB, Cooper AR, Ness AR, Emmett PM. Diet throughout childhood and age at menarche in a contemporary cohort of
British girls. Public Health Nutr. 2010;13(12):2052-63. https://doi.org/10.1017/ S1368980010001461.

17. Wiley AS. Milk intake and total dairy consumption: associations with early menarche in NHANES 1999-2004. PLoS One. 2011;6(2):e14685. https://doi. org/10.1371/journal.pone.0014685.

18. Ramezani Tehrani F, Moslehi N, Asghari G, Gholami R, Mirmiran P, Azizi F. Intake of dairy products, calcium, magnesium, and phosphorus in childhood and age at menarche in the Tehran lipid and glucose study. PLoS One. 2013;8(2):e57696. https://doi.org/10.1371/journal.pone.0057696.

19. Carwile JL, Willett WC, Wang M, Rich-Edwards J, Frazier AL, Michels KB. Milk consumption after age 9 years does not predict age at menarche. J Nutr. 2015 Aug;145(8):1900-8. https://doi.org/10.3945/jn.115.214270.

20. Jansen EC, Marín C, Mora-Plazas M, Villamor E. Higher childhood red meat intake frequency is associated with earlier age at menarche. J Nutr. 2015; 146(4):792-8. https://doi.org/10.3945/jn.115.226456.

21. Gaskins AJ, Pereira A, Quintiliano D, Shepherd JA, Uauy R, Corvalán C, et al. Dairy intake in relation to breast and pubertal development in Chilean girls. Am J Clin Nutr. 2017;105(5):1166-75. https://doi.org/10.3945/ajcn.116.1503 59.

22. Azizi F, Ghanbarian A, Momenan AA, Hadaegh F, Mirmiran P, Hedayati M, et al. Prevention of non-communicable disease in a population in nutrition transition: Tehran lipid and glucose study phase II. Trials. 2009:10(1):5. https://doi.org/10.1186/1745-6215-10-5.

23. Mirmiran P, Esfahani FH, Mehrabi Y, Hedayati M, Azizi F. Reliability and relative validity of an FFQ for nutrients in the Tehran lipid and glucose study. Public Health Nutr. 2010;13(05):654-62. https://doi.org/10.1017/\$13 68980009991698.

24. Esfahani FH, Asghari G, Mirmiran P, Azizi F. Reproducibility and relative validity of food group intake in a food frequency questionnaire developed for the Tehran lipid and glucose study. J Epidemiol. 2010;20(2):150-8. https://doi.org/10.2188/jea.JE20090083.

25. de Onis M, Onyango AW, Borghi E, Siyam A, Nishida C, Siekmann J. Development of a WHO growth reference for school-aged children and adolescents. Bull World Health Organ. 2007;85(09):660-7. https://doi.org/1 0.2471/BLT.07.043497.

26. Song M, Giovannucci E. Substitution analysis in nutritional epidemiology: proceed with caution. Eur J Epidemiol. 2018;33(2):137-40. https://doi.org/1 0.1007/s10654-018-0371-2

27. Harris C, Flexeder C, Thiering E, Buyken A, Berdel D, Koletzko S, et al. Changes in dietary intake during puberty and their determinants: results from the GINIplus birth cohort study. BMC Public Health. 2015;15(1):841. https://doi.org/10.1186/s12889-015-2189-0.

28. Soliman A, De Sanctis V, Elalaily R. Nutrition and pubertal development. Indian J Endocrinol Metab. 2014;18(Suppl 1):S39-47. https://doi.org/10.41 03/2230-8210.145073.

\section{Publisher's Note}

Springer Nature remains neutral with regard to jurisdictional claims in published maps and institutional affiliations.

Ready to submit your research? Choose BMC and benefit from

- fast, convenient online submission

- thorough peer review by experienced researchers in your field

- rapid publication on acceptance

- support for research data, including large and complex data types

- gold Open Access which fosters wider collaboration and increased citations

- maximum visibility for your research: over $100 \mathrm{M}$ website views per year

At BMC, research is always in progress.

Learn more biomedcentral.com/submissions 